\title{
FACTORS INFLUENCING SMOKING BEHAVIOURS AMONG MALE ADOLESCENTS IN KUANTAN DISTRICT
}

M. Y. Rapeah, Y. Munirah, O. Latifah, K. Faizah, S. Norsimah, M. Maryana, R. Saub. Factors influencing smoking behaviours among male adolescents in Kuantan district. Annal Dent Univ Malaya 2008; 15(2): 77-81.

\begin{abstract}
The aims of this study were to determine the prevalence and factors that influenced smoking behaviours among male adolescents in Kuantan, Pahang. A cross-sectional study was conducted among the form four male students in Kuantan District. Three hundred and twenty three students were randomly selected from eight secondary schools. A self-administered questionnaire was distributed to all the respondents. Almost half of the sample was smokers (45.8\%) and half of them were Malays (53.1\%). Students whose parents had lower level of occupation were more likely to smoke (58.8\%). Among smokers, 34.5\% of them smoked since primary school and a majority $(91.7 \%)$ smoked 10 or less cigarettes per day. Half of them (53.4\%) reported that they bought loose cigarettes and most of them used their school pocket money to purchase the cigarettes $(81.7 \%)$. From the multivariate analysis, it was found that Non-Science Stream classes $(\mathrm{OR}=3.92,95 \% \mathrm{CI}=2.10,7.32)$, peers' smoking $(\mathrm{OR}=6.07,95 \% \mathrm{CI}=2.32,15.92)$, and attitude towards smoking $(\mathrm{OR}=21.93,95 \% \mathrm{CI}=$ $9.71,49.51)$ were significantly associated with smoking habit. The prevalence of smoking among male adolescents was considerably high in this population. It is recommended that antismoking activities in school be carried out regularly and should involve an active participation from the adolescents themselves since peers have great influence on smoking habits.
\end{abstract}

Key words: smoking behaviour, cross-sectional study, adolescent

\section{INTRODUCTION}

It is well known that smoking is hazardous not only to the general health but also to the oral health. It is estimated that 10,000 deaths yearly in Malaysia were attributed to smoking (1). Studies have found that tobacco smoking is associated with an increase in oral cancer, periodontal disease and it also increases the likelihood of having a child with a cleft
Original Article

M.Y. Rapeah 1 , Y. Munirah1, O. Latifah ${ }^{1}$,
K. Faizah ${ }^{1}, \mathrm{~S}$. Norsimah $^{1}, \mathrm{M}$. Maryana $^{1}$
and R. Saub ${ }^{2}$
${ }^{1}$ Ministry of Health, Malaysia
Pegawai Pergigian U44,
Klinik Pergigian,
Poliklinik Komuniti Beserah,
25200 Kuantan, Pahang Darul Makmur
Tel: 609-5445633-117 (Off) 609-5444734 (Off)
Fax: 609-5444717
Email: rapeah_mohdyassin@yahoo.com
2Department of Community Dentistry,
Faculty of Dentistry,
University Malaya
Corresponding author: Rapeah Mohd Yassin

lip or palate (2). As such, dentists are also concerned with this habit.

The smoking prevalence in Malaysia is high especially among men and adolescents (3). The National Health and Morbidity Survey conducted nationwide in 1996 (4) reported that the prevalence of smoking among male adolescents in Malaysia was $30.7 \%$.

Studies have estimated that the smoking initiation age is between the ages of 11 to 15 years old $(5,6)$. The younger the age they start to smoke, the more likely they are to become a regular smoker in adulthood (7). A report from the US Surgeon General (US Department of Health and Human Service, 1988) states that most people will remain as non smokers if they do not smoke during their high school years $(5,6)$. Thus, it is important for us to ensure that our adolescents do not start smoking at this critical age.

The prevalence of ever smokers in Pahang was reported to be the second highest $(37.3 \%)$ after Kelantan (38.3\%), especially among male adults aged 18 years old and above (8). Thus, it is a concern of health professionals including oral health professionals in Pahang to look into this matter seriously. In order to plan an effective programme to curb with this problem, information on the factors that influence people to smoke is required. Thus, this study was aimed to determine the prevalence, pattern of smoking, reason for smoking and to identify factors that influence smoking behaviour among male adolescents in Kuantan, Pahang. 


\section{METHODS}

A cross-sectional study using a self administered questionnaire was conducted in October 2006. The target population was Form four male students in Kuantan district. A set of self-administered questionnaire was designed based on a study done by Zhang et al (9). The questionnaire was face validated by two Dental Public Health Officers. Prior to actual data collection, pre testing was done on thirty subjects.

The questionnaire contained questions on respondents' background (race, location of school, class stream, parent's occupation), smoking status, pattern of smoking (when they start to smoke, number of cigarettes smoke per day, quantity of cigarette bought each time, source of money to buy cigarettes), reason to start smoking, knowledge on smoking (5 questions with three point likert scale) and attitude towards smoking (6 questions with 5 points likert scale). Composite score was calculated for knowledge and attitude.

The sample size was calculated using a single proportion formula, based on the adolescence smoking prevalence of $16.7 \%$ (4) and detectable difference estimated by $4 \%$, which was based on medical expert opinion and allowing the alpha error at 0.05 . The sample size required was 274 .

The list of secondary schools in Kuantan district was obtained from Kuantan District Education Office and the list served as the sampling frame. A total of thirty five secondary schools were listed in this list. Boarding schools, Islamic Schools, Chinese School and Technical Schools were excluded from the list. These schools were excluded because they are special schools. After excluding these schools, due to cost and time constrains, only eight schools were randomly selected from the final list. Then, from each school, thirty percent of the male form four students were randomly selected. A total of 323 students were finally selected after considering $15 \%$ non-response rate.

Data collection was conducted in the school hall for each of the selected school. Prior to the distribution of the questionnaire, the purpose of the study was explained and the confidentiality was informed to the respondents. Students were assured that their smoking status will not be disclosed to parents or teachers.

The data was entered into SPSS version 11.0 software and analysed using STATA version 7.0. Univariate analysis, using simple logistic regression, was performed to assess the association between smoking status and socio demographic characteristics, knowledge on smoking, intrapersonal factors, and personal factors. Variables with significant associations were then analysed using multiple logistic regression to determine the association between these factors and smoking status.

\section{RESULTS}

Table 1 shows the socio-demographic characteristics of the respondents by smoking status. The mean age of the total sample was 15.8 years $(\mathrm{sd}=0.4)$. The proportion of smokers and non smokers were almost equally distributed in both rural and urban schools.

Overall smoking prevalence was $45.8 \%$. Slightly more than half $(53.1 \%)$ of the Malay respondents were smokers. Higher proportion of students from non-science stream classes were smokers compared to students from Science Stream. Students whose parents had lower level of occupation (partly skilled and non-skilled) were more likely to smoke $(58.8 \%)$.

Table 2 shows the smoking pattern of the respondents. About two third of the smokers started the smoking habit during their secondary schools. However, slightly more than one third of the

Table 1. Socio-demographic characteristics of the respondents

\begin{tabular}{lccr}
\hline Variables & $\begin{array}{c}\text { Smokers } \\
(n=148)\end{array}$ & $\begin{array}{c}\text { Non-Smokers } \\
(n=175)\end{array}$ & Total \\
\hline & $n(\%)$ & $n(\%)$ & \\
$\begin{array}{l}\text { Location of Schools } \\
\text { Urban }\end{array}$ & $74(43.0)$ & $98(57.0)$ & 172 \\
$\quad$ Rural & $74(49.0)$ & $77(51.0)$ & 151 \\
Grade/stream of class & & & \\
$\quad$ Science & $28(23.0)$ & $94(77.0)$ & 122 \\
$\quad$ Non-Science & $120(59.7)$ & $81(40.3)$ & 201 \\
Race & & & \\
$\quad$ Others & $9(14.8)$ & $52(85.2)$ & 61 \\
$\quad$ Malay & $139(53.1)$ & $123(46.9)$ & 262 \\
Parents' Occupation* & & & \\
$\quad$ Skilled & $74(37.6)$ & $123(62.4)$ & 197 \\
$\quad$ Partly skilled \& below & $67(58.8)$ & $47(41.2)$ & 114 \\
\hline
\end{tabular}

* Number do not add up due to missing data

Table 2. Pattern of smoking among respondents $(n=148)$

\begin{tabular}{lc}
\hline Variables & $\mathrm{n}(\%)$ \\
\hline Started smoking* & \\
Level 1 (primary school) & $5(3.4)$ \\
Level 2 (primary school) & $46(31.1)$ \\
Form 1 to 3 & $88(60.3)$ \\
Form 4 & $7(4.8)$ \\
Number of cigarette(s) smoked / day* & \\
$1-5$ sticks & $99(74.4)$ \\
$6-10$ sticks & $23(17.3)$ \\
$11-20$ sticks & $9(6.8)$ \\
Uncertain & $2(1.5)$ \\
Quantity of cigarette(s) bought each time & \\
Loose cigarettes & $79(53.4)$ \\
Box (es) & $69(46.6)$ \\
Source of money to buy cigarette(s) & \\
School pocket money & $121(81.7)$ \\
Part time work & $3(2.0)$ \\
Given free by someone & $24(16.2)$ \\
\hline
\end{tabular}

* Number do not add up due to missing data 
smokers started the smoking habit since primary school. Majority of the smokers smoked 10 or less cigarettes per day. About $53 \%$ of the smokers bought a loose cigarette and most of them used their school pocket money to buy it $(81.7 \%)$.

The most common reason given by the respondents for starting smoking was "wanted to try" $(68.9 \%)$ followed by "peers influence" (56.1\%). However, almost $70 \%$ of the smokers did not agree that they smoked because they wanted to be trendy (Table 3).

Table 4 shows the univariate analysis, using a simple logistic regression, for all the independent variables included in the study. There were seven variables showed significant association with the smoking status; they were type of class stream, race, parents' occupation, fathers' smoking status, peers' smoking status, knowledge on smoking and attitude towards smoking.
Multiple Logistic Regression analysis showed that type of class stream, peers' smoking, and attitude towards smoking were significantly associated with the respondents smoking status. Hosmer-Lemeshow test for fitness of model was not significant $(\mathrm{p}$-value $=0.285$ at $\mathrm{df}=8)$. Therefore, the

Table 3. Reasons for the respondents to start smoking

$$
(n=148)
$$

\begin{tabular}{lccc}
\hline Variables & $\begin{array}{c}\text { Agreed } \\
\mathrm{n}(\%)\end{array}$ & $\begin{array}{c}\text { Not sure } \\
\mathrm{n}(\%)\end{array}$ & $\begin{array}{c}\text { Do not agree } \\
\mathrm{n}(\%)\end{array}$ \\
\hline Wanted to try & $102(68.9)$ & $35(23.6)$ & $11(7.4)$ \\
Peer influence & $83(56.1)$ & $36(24.3)$ & $29(19.6)$ \\
Adult influence & $58(39.2)$ & $43(29.1)$ & $47(31.8)$ \\
To reduce stress & $54(36.5)$ & $41(27.7)$ & $53(35.8)$ \\
To become trendy* & $2(1.7)$ & $13(11.0)$ & $103(87.3)$ \\
\hline
\end{tabular}

* Number do not add up due to missing data

Table 4. Univariate analysis for association between factors and smoking status

\begin{tabular}{|c|c|c|c|c|c|}
\hline Variables & $\begin{array}{c}\text { Smokers } \\
(n=148)\end{array}$ & $\begin{array}{c}\text { Non-Smokers } \\
(n=175)\end{array}$ & $\begin{array}{l}\text { Unadjusted OR } \\
(95 \% \mathrm{Cl})\end{array}$ & $\begin{array}{l}\text { LR Stat. }{ }^{1} \\
\quad(\mathrm{df})\end{array}$ & $\mathrm{P}$ - value \\
\hline & $\mathrm{n}(\%)$ & $\mathrm{n}(\%)$ & & & \\
\hline \multicolumn{6}{|l|}{ Location of Schools } \\
\hline Urban & $74(43.0)$ & $98(57.0)$ & $1.27(0.82,1.97)$ & 1.16 & 0.282 \\
\hline Rural & $74(49.0)$ & $77(51.0)$ & 1 & $(1)$ & \\
\hline \multicolumn{6}{|l|}{ Grade/stream of class } \\
\hline Science & $28(23.0)$ & $94(77.0)$ & 1 & 43.05 & $<0.001$ \\
\hline Others & $120(59.7)$ & $81(40.3)$ & $4.97(2.99,8.26)$ & (1) & \\
\hline \multicolumn{6}{|l|}{ Race } \\
\hline Others & $9(14.8)$ & $52(85.2)$ & 1 & 32.23 & $<0.001$ \\
\hline Malay & $139(53.1)$ & $123(46.9)$ & $6.53(3.09,13.80)$ & (1) & \\
\hline \multicolumn{6}{|l|}{ Parents' Occupation } \\
\hline Skilled & $74(37.6)$ & $123(62.4)$ & $2.37(1.48,3.80)$ & 13.14 & $<0.001$ \\
\hline Partly skilled \& below & $67(58.8)$ & 47 (41.2) & 1 & $(1)$ & \\
\hline \multicolumn{6}{|l|}{ Fathers' smoked } \\
\hline No \& Don’t Know & $56(36.6)$ & $97(63.4)$ & 1 & 10.20 & 0.002 \\
\hline Yes & $92(54.1)$ & $78(45.9)$ & $2.04(1.31,3.19)$ & $(1)$ & \\
\hline \multicolumn{6}{|l|}{ Mothers' smoked } \\
\hline No \& Don't Know & $145(45.6)$ & $173(54.4)$ & 1 & 0.41 & 0.522 \\
\hline Yes & $3(60.0)$ & $2(2.1)$ & $1.80(0.30,10.86)$ & $(1)$ & \\
\hline Relatives' smoked & & & & & \\
\hline No \& Don't Know & $54(50.9)$ & $52(49.1)$ & 1 & 1.67 & 0.197 \\
\hline Yes & $94(43.3)$ & $123(56,7)$ & $0.74(0.46,1.17)$ & $(1)$ & \\
\hline \multicolumn{6}{|l|}{ Peers' smoked } \\
\hline No \& Don’t Know & $7(10.0)$ & $63(90.0)$ & 1 & 52.60 & $<0.001$ \\
\hline Yes & $141(55.7)$ & $112(44.3)$ & $11.33(4.99,5.71)$ & $(1)$ & \\
\hline \multicolumn{6}{|l|}{ Teachers' smoked } \\
\hline No \& Don’t Know & $96(49.5)$ & $100(50.5)$ & 1 & 2.79 & 0.095 \\
\hline Yes & $50(40.0)$ & $75(60.0)$ & $0.68(0.43,1.07)$ & $(1)$ & \\
\hline Knowledge (mean score) & $1.4(0.32)^{2}$ & $1.3(0.30)^{2}$ & $2.71(1.32,5.66)$ & $\begin{array}{c}7.48(1) \\
\text { (1) }\end{array}$ & 0.006 \\
\hline Attitude towards smoking (mean score) & $1.9(0.49)^{2}$ & $1.3(0.30)^{2}$ & $27.87(12.93,60.05)$ & $\begin{array}{c}116.67 \\
\text { (1) }\end{array}$ & $<0.001$ \\
\hline
\end{tabular}


Table 5. Association between factors and smoking status among male adolescents using a Multiple Logistic Regression

\begin{tabular}{|c|c|c|c|c|c|}
\hline Variables & $\begin{array}{l}\text { Smokers } \\
\text { No (\%) }\end{array}$ & $\begin{array}{c}\text { Non-Smokers } \\
\text { No }(\%)\end{array}$ & $\begin{array}{l}\text { Adjusted OR } \\
\qquad(95 \% \mathrm{Cl})\end{array}$ & $\begin{array}{l}\text { LR stat. }{ }^{2} \\
\text { (df) }\end{array}$ & $P$ value \\
\hline \multicolumn{6}{|l|}{ Grade / stream of classes } \\
\hline Science & $28(23.0)$ & $94(77.0)$ & 1 & & $<0.001$ \\
\hline Others & $120(59.7)$ & $81(40.3)$ & $3.92(2.10,7.32)$ & & \\
\hline \multicolumn{6}{|l|}{ Peer's smoking } \\
\hline No \& Don’t know & $7(10.0)$ & $63(90.0)$ & 1 & 162.20 & $<0.001$ \\
\hline Yes & $141(55.7)$ & $112(44.3)$ & $6.07(2.32,15.92)$ & (3) & \\
\hline Attitude towards smoking (mean score) & $1.9(0.49)^{1}$ & $1.3(0.30)^{1}$ & $21.93(9.71,49.51)$ & & $<0.001$ \\
\hline
\end{tabular}

1 mean (s.d)

model was fit. In this model the area under the curve was 0.874 .

\section{DISCUSSION}

The main aim of this study was to identify factors that contribute to smoking behaviour among adolescents in Kuantan District of Pahang. In Malaysia, studies on smoking among secondary students have been widely reported. Smoking prevalence in Pahang was reported to be the second highest (37.3\%) after Kelantan (38.3\%) (8). Since smoking habit was prevalent among the male adolescents, the present study was focused on this group of population.

In this study we found that the prevalence of smoking among the male adolescents in Kuantan, Pahang was higher (45.8\%) than a similar study conducted in Kelantan (34.6\%) by Naing et al (10). However, the finding was similar with the other study conducted by Fadhli et al (11) also in Kelantan $(44.2 \%)$.

A systematic review of thirty-five studies concluded that smoking status was consistently related to school performance, educational aspirations, and commitment to school (10). Students who do well in school, who have high academic achievement, and who are highly committed to school are less likely to smoke than those who do not possess these characteristics (12). Study by Naing et al showed that the academic performance of the students was significantly associated with the smoking status of the students where smokers had poor academic performance than non-smokers (10). The present study also showed similar trend where non-science stream students were more likely to smoke than the science stream students. In the Malaysian education system, the science stream students are usually selected among those who have achieved excellent results in the lower secondary examination. As such, those in the science stream could be considered as high academic achievers.

Adolescents are easily influenced by the environment where they live in and people surrounding them. The present study found that peer's influence was one of the importance factors to influence the respondents to smoke. Similar finding was also observed among adolescents in China (9), Taiwan (13) and in Kelantan, Malaysia (10).

Besides the influence of peers, Wen et al also found that parents played an important role in influencing the adolescents' smoking status and concluded that parental influence was more important than peer's influence in the Asian population (13). However, the study in Kelantan (10) and the present study reported that parental influences were not as important as the influence by the peers.

Our finding indicated that positive attitude towards smoking was strongly associated with smoking status. Similar finding was also observed by Zhang et al (9). It is not surprising that negative values contribute to bad habit such as smoking especially among adolescents despite knowing the hazards of smoking.

Smoking is known to contribute to many health problems. Thus, anti-smoking programme needs to be planned to prevent this habit. Perhaps, the school can play an important role in promoting antismoking habits since most of the adolescents' time is spent in school. It is recommended that antismoking activities in school be carried out regularly and should involve active participation from the adolescents themselves since peers have a great influence on smoking habits. Since there is an established school dental programme in Malaysia, dentists and dental nurses should incorporate antismoking campaign in their oral health education as well as offering smoking cessation advice for adolescents to stop smoking. 


\section{ACKNOWLEDGEMENT}

We would like to express our appreciation to Pahang State Education Department, Kuantan District Education Department, headmasters, teachers and students from eight schools who participated in this study.

\section{REFERENCES}

1. Ministry of Health. "Tak Nak! Setiap sedutan membawa padah". Ministry of Health, 2004.

2. Gordon J. Cigarette Smoking: A factor in many oral health problems. Www.dentalzonecomfort com. Accessed on 29 March 2006.

3. Morrow M \& Barraclough S. Tobacco control and gender in Southeast Asia. Paru 1: Malaysia and the Philippines. Health Promotion International. 2003; 18, 3: 255-263.

4. Abdulah S. National Health Morbiditi Survey: Health risk behaviour among adolescents. Ministry of Health Malaysia. 1999

5. Conrad, Karen M, Brian R et al. Why Children Start Smoking Cigarettes: Predictors of Onset. British Journal of Addiction 1992; 87, 12: 1711 1724.

6. Stanton WR and Silva PA. A longitudinal study of the influence of parents and friends on children's initiation of smoking. Journal of Applied Developmental Psychology 1992; 13: 423-434.
7. Paavola M, Vartiainen E., Haukkala A. Smoking from Adolescence to Adulthood. The effects of parental and own socioeconomic status. European Journal of Public Health 2004; 14: 417-421.

8. Haniza MA, Maimunah AH, Rusilawati J, Latifah S \& Suraya A. National Health and Morbidity Survey 1996: Smoking among Adults. Ministry of Health Malaysia. 1999; 15.

9. Zhang L, Wang W, Zhao Q, Vartiainen E. Psychososial predictors of smoking among secondary school students in Henan, China. Health Education Research 2000; 15, 4: 415-422.

10. Naing NN, Ahmad Z, Musa R, Abdul Hamid FR, Ghazali H \& Abu Bakar MH. Factors Related to Smoking Habits of Male Adolescents. Tobacco Induced Diseases 2004; 2, 3: 133-140.

11. Fadhli M, Zulkifli A. Associated factors of smoking behaviour and the association of smoking with lung function amongst male secondary school students in Kota Bharu, Kubang Kerian, Kelantan: University Sains Malaysia, 2002. Dissertation.

12. Tyas SL and Pederson LL. Psychososial factors related to adolescent smoking: A critical review of the literature. Tobacco control 1998; 7: 409420.

13. Wen CP., Tsai SP., Cheng TY., Hsu CC., Chen $\mathrm{T} \&$ Lin HS. Role of parents and peers in influencing the smoking status of high school students in Taiwan. Tobacco Copntrol 2005; 14: i10-i15. 